\title{
PENGARUH KEPERCAYAAN DAN KUALITAS PELAYANAN TERHADAP MINAT KUNJUNGAN WISATAWAN PADA HOTEL DANTE DI KABUPATEN GIANYAR
}

\author{
Ni Wayan Astari ${ }^{1}$ \\ Putu Gede Denny Herlambang ${ }^{2}$ \\ ${ }^{1,2}$ Fakultas Ekonomi Universitas Ngurah Rai, Bali, Indonesia
}

\begin{abstract}
ABSTRAK
Untuk mempertahankan agar tetap bertahan ditengah persaingan yang ketat, maka mereka berlomba lomba menawarkan nilai lebih yang dapat menarik minat konsumen. Karena bisnis ini berhubungan dengan orangorang sebagai pelanggan, maka Pelanggan yang puas dan loyal merupakan peluang untuk mendapatkan pelanggan baru yang merupakan faktor yang menentukan keberhasilan bisnis ini. Perumusan masalah dalam penelitian ini adalah : Apakah kepercayaan dan kualitas pelayanan secara parsial maupun simultan berpengaruh terhadap minat kunjungan wisatawan pada Hotel Dante di Gianyar? Tujuan penelitian adalah Untuk mengetahui kepercayaan dan kualitas pelayanan secara parsial maupun secara simultan berpengaruh terhadap minat kunjungan wisatawan pada Hotel Dante Gianyar. Jumlah sampel ditentukan dengan metode sensus sebanyak 25 orang wisatawan yang berkunjung di Hotel Dante Gianyar. Data dianalisis dengan menggunakan uji asumsi klasik, analisis regresi linier berganda, analisis determinasi, uji signifikansi simultan (F-test) dan uji signifikansi parsial (t-test). Hasil penelitian menunjukkan ada pengaruh yang positif dan signifikan secara simultan maupun parsial antara Pengaruh Kepercayaan Dan Kualitas Pelayanan Terhadap Minat Kunjungan Wisatawan Pada Hotel Dante Gianyar.
\end{abstract}

Kata kunci : Kepercayaan , Kualitas Pelayanan, Minat Kunjungan

\section{ABSTRACT}

To maintain in order to stay on the misdt of intense competition, they compete to order offer more value that can attractconcumers, satisfied and loyal customers are opportunities to get new costumers which are the factors that determine the success of this business. The formulation of the problem inthis study is: Does the trust and quality of service partially or simultaneously influence the interest of tourist visits at the Dante Hotel in Gianyar: The purpose of the sutdy was to determine the trust and quality of service partially or simultaneously influnce the interest of tourist visits at Hotel Dante Gianyar. The number of sampels was determined by a census method of 25 tourists visiting the Dante Hotel Gianyar. Data were analyzed using classic assumption test, multiple linear regression analysis, analysis of determination, simultaneous significance test ( $F$-test) and partial significance test ( $t$-tes). The result showed that there were positive and significant effects simultaneously and partially between the influence of trust and service quality on the interest of tourist visits at the Dante Hotel Gianyar.

Keywords: Trust, Service Quality, Visit Interest 


\section{PENDAHULUAN}

hotel merupakan bisnis jasa akomodasi yang di dalamnya terdapat unsur pelayanan, kenyamanan, serta fasilitas penginapan yang dibutuhkan bagi mereka yang menghendaki sarana penginapan untuk kepentingan keluarga maupun liburan. Berkaitan dengan pemanfaatan waktu luang untuk liburan maka bisnis ini menunjang industri pariwisata yang menyediakan berbagai fasilitas pertemuan penjamuan dan sebagainya. Karena bisnis ini berhubungan dengan orang-orang sebagai pelanggan, maka Pelanggan yang puas dan loyal merupakan peluang untuk mendapatkan pelanggan baru yang merupakan faktor yang menentukan keberhasilan bisnis ini.

Perusahaan yang bergerak di bidang produk haruslah dapat mempertahankan reputasi yang baik di mata pelanggannya. Kualitas layanan yang baik dan berkualitas akan cenderung memberikan kepuasan yang lebih kepada pelanggan yang menggunakan jasa pada perusahaan tersebut. Tanpa memperhatikan kualitas pelayanan maka jangan harap perusahaan dapat terus mempertahankan image di mata pelanggan. Dengan mengutamakan pelayanan yang baik dan memberikan kenyamanan maka pembeli akan memudahkan perusahaan mencapai tujuan perusahaan yaitu mencapai laba yang maksimal melalui peningkatan jumlah pembeli oleh pelanggan secara terus menerus.

Peningkatan kualitas pelayanan adalah salah satu isu yang sangat krusial dalam manajemen, baik dalam sektor pemerintah mauun swasta. Hal ini terjadi karena di satu sisi tuntutan masyarakat terhadap perbaikan kualitas pelayanan dari tahun menjadi semakin besar, sedangkan disisi lain praktek penyelenggaraan pelayanan tidak mengalami perbaikan yang berarti (purwoastuti dan walayani, 2015:1)

Peningkatan jumlah pembeli ini dapat terjadi jika pelanggan puas atas fasilitas pelayanan yang ditawarkan perusahaan.Untuk mempertahankan agar tetap bertahan ditengah persaingan yang ketat, maka mereka berlomba lomba menawarkan nilai lebih yang dapat menarik minat konsumen. Dari aneka makanan,hiburan,serta fasilitas lain yang menjadi ciri khas dimata konsumen. Salah satu diantaranya yaitu Hotel yang bernama Hotel Dante beralamat di jl. Hasanudin I no 3 Gianyar yang terletak di tengah - tengah perumahan yang cukup padat penduduknya yang bertujuan untuk menikmati istirahat setelah berwisata maupun tugas bisnis dengan lebih nyaman. Berdasarkan wawancara saya dengan pegawai disana mengenai data angka kunjungan ulang hotel selama 2 tahun terakhir menunjukkan jumlah wisatawan yang kembali menggunakan layanan hotel masih sedikit. Kunjungan wisatawan yang terus menurun menunjukkan bahwa strategi pemasaran yang dijalankan Hotel Dante tidak berjalan dengan baik sehingga minat wisatawan untuk melakukan kunjungan ulang rendah. Dari survey awal yang dilakukan penyebab turunnya minat kunjungan ulang wisatawan seperti faktor pengalaman yang tidak menyenangkan di masa lalu pada saat melakukan kunjungan sehingga wisatawan enggan untuk datang kembali, pencarian informasi yang minim untuk mendapatkan loksi karena belum banyak orang yang mengetahui tempat tersebut. Dengan infomasi yang ada, maka dalam penelitian ini penulis memilih Hotel Dante sebagai obyek penelitian, dengan maksud untuk mengetahui apakah kepercayaan dan kualitas pelayanan dapat berpengaruh atau tidak terhadap minat kunjungan wisatawan.

Berdasarkan pernyataan diatas maka penulis memfokuskan penelitian dengan judul "Pengaruh Kepercayaan Dan Kualitas Pelayanan Terhadap Minat Kunjungan Wisatawan Pada Hotel Dante Gianyar".

\section{METODE PENELITIAN}

Penelitian ini menggunakan pendekatan kuantitatif dengan metode survei. Pendekatan ini berlandaskan pada positivisme digunakan untuk meneliti pada populasi atau sampel tertentu, pengumpulan data menggunakan instrumen penelitian, 
analisis data bersifat kuantitatif/statistik dengan tujuan untuk menguji hipotesis yang telah ditetapkan (Sugiyono, 2015:35). Menggunakan metode survei karena penelitian dilakukan pada suatu populasi dan data yang dipelajari adalah data dari sampel yang diambil dari populasi tersebut. Populasi dalam penelitian ini adalah Populasi dalam penelitian ini adalah 50 orang wisatawan yang berkunjung pada Hotel Dante Gianyar. Jumlah sampel dalam penelitian ditentukan berdasarkan rumus aksidental dan ukuran sampel yang diperoleh sebesar 25 orang. Teknik pengumpulan data dilakukan dengan observasi, kuesioner dan wawancara. Instrumen penelitian dilakukan uji validitas dan reliabilitas. Pengolahan data menggunakan perhitungan statistik regresi linier berganda berdasarkan hasil perolehan data dari jawaban responden dari kuesioner yang diberikan. Data dikuantitatifkan terlebih dahulu dengan metode skala likert yaitu dengan memberikan skor kepada masing-masing indikator variabel yaitu dari skor 1 sampai dengan skor 5 sebagai berikut : Sangat Tidak Setuju (STS) diberi skor 1, Tidak Setuju (TS) diberi skor 2, Netral (N) diberi skor 3, Setuju (S) diberi skor 4, sangat Setuju (SS) diberi skor 5. Teknik analisis data dalam penelitian ini menggunakan pendekatan kuantitatif yaitu analisis statistik inferensial, terdiri dari: uji asumsi klasik, analisis regresi linier berganda, analisis determinasi, uji signifikansi parsial (t-test) dan uji signifikansi simultan ( $F$-test $)$.

\section{HASIL DAN PEMBAHASAN Uji instrumen}

Sebelum menganalisis data, terlebih dahulu dilakukan uji validitas dan reliabilitas terhadap data yang diperoleh dari instrumen penelitian. Jika instrumen penelitian dinyatakan valid dan reliable, berarti instrumen layak digunakan sehingga mampu mengukur variabel sebagaimana mestinya.

Uji Validitas dilakukan untuk melihat ketepatan dan kecermatan instrumen sebagai alat ukur. Tingkat validitas instrumen dapat dilihat dengan membandingkan nilai koefisien korelasi (Pearson Correlation) instrumen dengan nilai $\mathrm{R}$ tabel. Jika nilai koefisien korelasi > $\mathrm{R}$ tabel maka item pernyataan adalah valid. Hasil Uji Validitas Instrumen Karena nilai $\mathrm{r}$ hitung yang dilihat dari Pearson Correlattion pada item_1 sebesar 0,535> $\mathrm{r}$ tabel 0,195 , maka sebagaimana dasar pengambilan keputusan dalam uji validitas dapat simpulkan bahwa item_1 adalah valid. Uji reliabilitas dilakukan untuk mengetahui sejauh mana hasil pengukuran tetap konsisten, jika dilakukan pengukuran dua kali atau lebih terhadap gejala dengan gejala yang sama dengan menggunakan alat ukur yang sama.Uji reliabilitas di bantu dengan bantuan program SPSS Version 18.0 for Windows. Adapaun hasilnya disajikan pada tabel 4.2 sebagai berikut :

Tabel 1

Hasil Uji Reliabilitas Instrumen

Reliability Statistics

\begin{tabular}{|r|r|}
\hline $\begin{array}{c}\text { Cronbach's } \\
\text { Alpha }\end{array}$ & N of Items \\
\hline .723 & 12 \\
\hline
\end{tabular}

Sumber: Pengolahan Data Penelitian Pada Lampiran

Berdasarkan tabel diatas, dari 12 buah item dengan nilai Cronbach's Alpha sebesar 0,723>0,05. Maka sebagaian dasar pengambilan keputusan dalam uji Reliabilitas adalah reliabel atau konsisten. 


\section{Uji Asumsi Klasik}

Sebelum dianalisis dengan teknik analisis regresi linier berganda, maka model persamaan regresi harus melalui uji asumsi klasik agar hasil uji hipotesis tidak bias. Berikut disajikan hasil uji asumsi klasik yang diolah dengan bantuan program SPSS version 22 For Windows yang terdiri dari uji normalitas, uji multikolinearitas dan uji heteroskedastisitas.
Untuk mendeteksi apakah data berdistribusi normal atau tidak dapat dilakukan secara statistik, dengan uji statistik non-parametrik Kolmogrov-Smirnov(K-S).Uji Normalitas di bantu dengan bantuan program SPSS Version 18.0 for Windows. Adapaun hasilnya disajikan pada tabel 2 sebagai berikut:

Tabel 2

Hasil Uji Normalitas

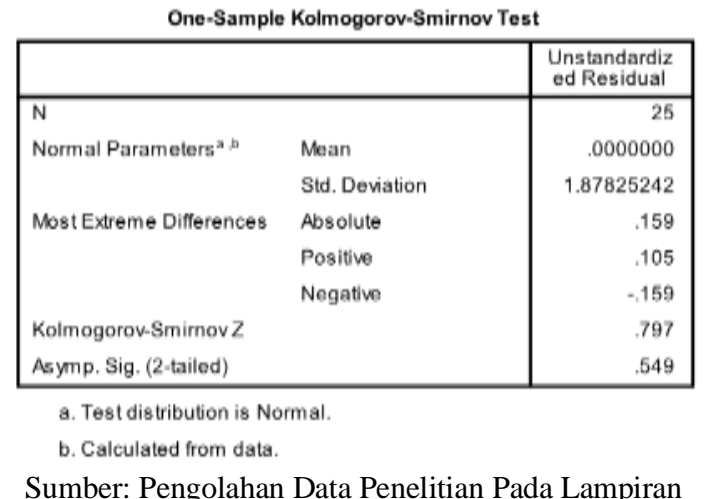

Berdasarkan tabel diatas, dilihat pada Asymp. Sig. (2-tailed) sebesar 0,549 lebih besar dari 0,05. Maka sesuai pengambilan keputusan dalam uji normalitas kolmogorov smirnov diatas, dapat disimpulkan data berdistribusi normal. Uji heteroskedastisitas bertujuan menguji apakah dalam model regresi terjadi ketidaksamaan variance dari residual satu pengamatan kepengamatan yang lain. Mendeteksi ada atau tidaknya heteroskedastisitas dilakukan secara statistik, dengan menggunakan uji Glejser. Uji Heteroskedasitas di bantu dengan bantuan program SPSS Version 18.0 for Windows. Adapun hasilnya disajikan pada tabel 3 sebagai berikut :

Tabel 3

Hasil Uji Heteroskedastisitas

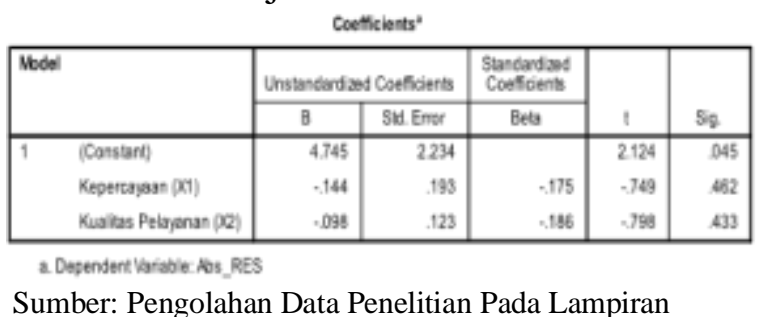

Sumber: Pengolahan Data Penelitian Pada Lampiran

Berdasarkan tabel diatas, dilihat pada nilai sig Kepercayaan (X1) adalah 0,462 dan Kualitas Pelayanan (X2) adalah
0,433. Karena nilai sig lebih besar maka tidak terjadi gejala heteroskedastisitas dalam model regresi. Uji multikolinearitas 
bertujuan untuk menguji apakah model regresi ditemukan adanya korelasi antara variabel bebas jika terjadi korelasi, maka terdapat problem multikolenearitas.Uji
Multikolinearitas di bantu dengan bantuan program SPSS Version 18.0 for Windows. Adapaun hasilnya disajikan pada tabel 4.4 sebagai berikut:

Tabel 4

Hasil Uji Multikolinearitas

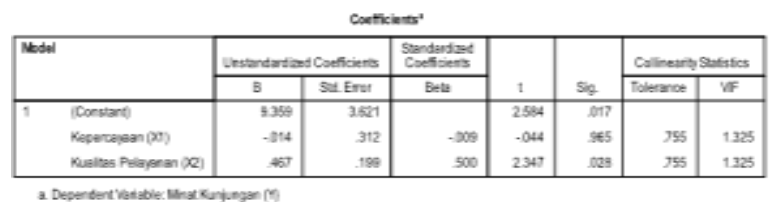

Sumber: Pengolahan Data Penelitian Pada Lampiran

Uji Regresi Linier Ganda

Berdasarkan tabel output "Coefficients" pada bagian "Collinearty Statistics"diketahui nilai Tolerance untuk variabel (X1) dan (X2) adalah 0,755lebih besar dari 0,10. Semestara, nilai VIF untukvariabel (X1) dan (X2) adalah $1,325<10,00$. Maka mengacu pada dasar pengambilan keputusan dalam uji multikolinearitas dapat disimpulkan bahawa tidak terjadi gejala multikolineritas dalam model regresi.
Analisis ini digunakan untuk mengetahui minat kunjungan sebagai variabel terikat yang dipengaruhi oleh analisis kepercayaan dan kualitas pelayanan sebagai variabel bebas. Uji regresi linier gandadi bantu dengan bantuan program SPSS Version 18.0 for Windows. Adapun hasilnya disajikan pada tabel 5 sebagai berikut

Tabel 5

Hasil Analisis Regresi Linier Berganda

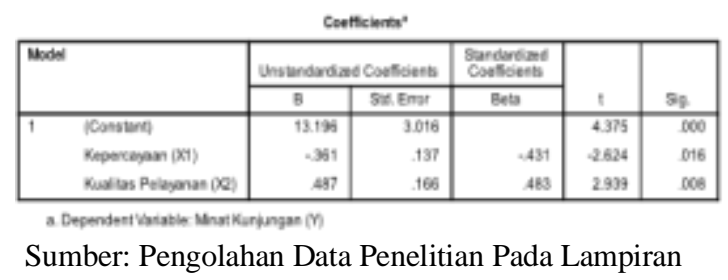

Berdasarkan hasil analisis dengan menggunakan SPSS diatas, diketahui $\mathrm{Y}=$ 13,196, X1 $=0,361$ dan $X 2=0,487$. Jadi $Y$ $=13,196+0,361+0,487=14,04$

\section{Analisis Determinasi}

Analisis determinasi untuk mengetahui jumlah digunakan

persentase kontribusi kepercayaan dan kualitas pelayanan terhadap minat kunjungan.Uji analisis determinasi di bantu dengan bantuan program SPSS Version 18.0 for Windows. Adapun hasilnya disajikan pada tabel 6 sebagai berikut : 
Tabel 6

Hasil Analisis Determinasi

\begin{tabular}{|l|l|r|r|r|}
\hline \multicolumn{7}{|c|}{ Model Summary } \\
\hline 1 & $\mathrm{R}$ & R Square & $\begin{array}{c}\text { Adjusted R } \\
\text { Square }\end{array}$ & $\begin{array}{c}\text { Std. Error of } \\
\text { the Estimate }\end{array}$ \\
\hline 1 & $.637^{\mathrm{a}}$ & .406 & .352 & 1.740 \\
\hline
\end{tabular}

a. Predictors: (Constant), Kualitas Pelayanan (X2),

Sumber: Pengolahan Data Penelitian Pada Lampiran

Berdasarkan hasil dilihat pada $\mathrm{R}$ Square 0,406. Karena besarnya $\mathrm{R}^{2}=0,406$. Koefisien determinasi (D) $=40 \%$ berarti bahwa besarnya kepercayaan dan kualitas pelayanan terhadap minat kunjungan adalah sebesar $\quad 40 \%$. Sedangkan sisanya dipengaruhi oleh faktor-faktor tidak dibahas dalam penelitian ini.

\section{Uji T-test}

Uji ini digunakan untuk menguji signifikansi koefisien regresi, sehingga diketahui pengaruh secara parsial antara hubungan kepercayaan dan kualitas pelayanan terhadap minat kunjungana dalah pengaruh yang positif dan signifikan atau hanya diperoleh secara kebetulan.

Tabel 7

Hasil Analisis Uji T-test

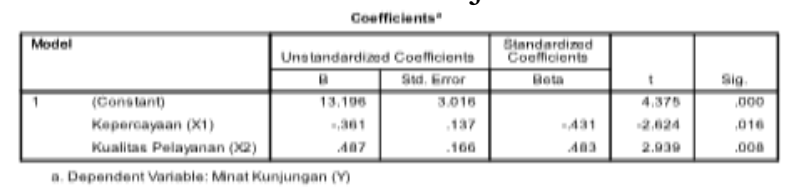

Sumber: Pengolahan Data Penelitian Pada Lampiran

Berdasarkan gambar 4.1 bahwa thitung $=2,939>\mathrm{t}$ tabel $=2,073$ oleh karena $t$ hitung berada pada daerah penolakan Ho, maka pengaruh kepercayaan terhadap minat kunjungan adalah signifikan.

\section{Uji F-test}

Uji ini digunakan untuk menguji signifikasi kepercayaan dan kualitas pelayanan berpengaruh positif dan signifikasi terhadap terhadap minat kunjungan secara simultan.

Tabel 7

Hasil Analisis Uji T-test

\begin{tabular}{|c|c|c|c|c|c|c|}
\hline \multicolumn{7}{|c|}{ ANOVA } \\
\hline Mod & & $\begin{array}{l}\text { Sum of } \\
\text { Squares }\end{array}$ & df & Mean Square & $\mathrm{F}$ & Sig. \\
\hline \multirow[t]{3}{*}{1} & Regression & 45.606 & 2 & 22.803 & 7.529 & $.003^{\circ}$ \\
\hline & Residual & 66.634 & 22 & 3.029 & & \\
\hline & Total & 112.240 & 24 & & & \\
\hline
\end{tabular}

a. Predictors: (Constant), Kualitas Pelayanan (X2), Kepercayaan (X1)

b. Dependent Variable: Minat Kunjungan ( $($ )

Sumber: Pengolahan Data Penelitian Pada Lampiran

Berdasarkan gambar 4.2 bahwa $\mathrm{F}$ hitung $=7,582>\mathrm{t}$-tabel $=3,44$ maka Ho ditolak dan ha diterim oleh karena $F$ hitung berada pada daerah penolakan Ho maka keercayaan dan kualitas pelayanan berpengaruh positif dan signifikan terhadap minat kunjungan wisatawan (hippotesis terbukti). 


\section{PENUTUP KESIMPULAN}

Berdasarkan hasil pembahasan yang telah diuraikan pada bab IV, maka dapat disimpulkan sebagai berikut : kepercayaan berpengaruh negative terhadap minat kunjungan wisatawan pada Hotel Dante di Kabupaten Gianyar. Hal ini di tunjukkan oleh nilai t hitung $=-2,624<\mathrm{t}$ tabel $=2,073$. Kualitas pelayanan berpengaruh positifndan signifikan terhadap minat kunjungan wisatawan pada hotel Dante di Kabupaten Gianyar. Hal ini dibuktikan olehnilai t hitung $=2,939>\mathrm{t}$ tabel $=2,073$. Kepercayaan dan kualita pelayanan berpengaruh positif dan signifikan secara simultan terhadap minat kunjungan wisatawan pada hotel Dante di Kabupaten Gianyar. Hal ini dinyatakan oleh nilai Fhitung $=7,582>$ Ftabel $=3,44$.

\section{SARAN-SARAN}

Berdasarkan hasil pembahasan dan simpulan yang telah diuraikan, maka yang dapat penulis sarankan kepada Hotel Dante Gianyar adalah sebagai berikut:

1. Kepada Hotel Dante Gianyar untuk meningkatkan kepercayaan dan kualitas pelayanan yang berguna untuk peningkatan minat kunjungan seperti memberikan jamuan selamat datang kepada para pengunjung agar merasa nyaman sehingga dapat bersaing dengan hotel yang lainnya.

2. Memberikan penghargaan kepada karyawan yang memiliki servis yang baik kepada pengunjung setiap bulannya baik berupa surat penghargaan maupun dalam bentuk materi.

3. Kualitas pelayanan yang dilakukan resepsionis harus lebih ditingkatkan dalam hal menginput data konsumen, dalam memberikan pelayanan yang cepat dan akurat serta kecepatanmerespon keinginan pelanggan.

4. Peneliti selanjutnya diharapkan dapat memperluas populasi penelitian, yaitu dengan menambah responden wisatawan yang berkunjung ke Hotel Dante Gianyar.

\section{DAFTAR PUSTAKA}

Arikunto,S. 2009. Metodologi Penelitian (edisi revisi). Yogyakarta Bina Aksara.

Ghozali, Imam. 2010. Aplikasi Analisis Multivariate dengan Program SPSS Semarang: Badan Penerbit Universitas diponegoro.

Ferdinand, Augusty. 2007. Metode lenelitian manajemen. Semarang: Badan Penerbit Universitas Diponegoro.

Keller, K. 2008. Manajemen Pemasaran. Edisi 12 jilid 2 (Ahli Bahasa oleh Benyamin), Molan Jakarta: PT Ineks.

Kotler, Philip, dan Kevin Lane Keller. 2009. Manajemen Pemasaran Jilis 2, edisi ketigas belas, terjemahan Bob Sabran, MM. Jakarta Penerbit Erlangga.

Nuraeni, Bellinda Sofia. 2014. Analisis Faktor-Faktor Yang Mempengaruhi Minat Kunjung Ulang Wisatawan Museum Ranggawarsita Semarang. Semarang.

Payne, A. 2005. Manajemen Pemasaranjasa. Jakarta: Salemba Empat.

Paliati. 2007. Pengaruh Nilai Pelanggan, Kepuasan Pelanggan terhadap Loyalitas Nasabah Tabungan Perbankan. Sulawesi Selatan.

Rosvita Dua Lembang. 2010. Analisis Pengaruh kualitas Produk, harga, promosi dan cuaca terhadap keputusan Pembelian The Siap Minum Dalam Kemasan Merek The Botol Sosro. Online. 
Pengaruh Kepercayaan dan Kualitas Pelayanan Terhadap Minat Kunjungan Wisatawan Pada Hotel Dante di Kabupaten Gianyar

Robbin, Stephen dan Mary Coulter, 2008.

Manajemen. Edisi Bahasa

Yogyakarta: Andi Offiset.

Indonesia, jilid 1, Jakarta. PT Indeks

Kelompok Gramedia.

Sugiyono. 2008. Metode Penelitian, Kuantitatif, Kualitatif Dan $R \& D$. Bandung: Alfabeta.

Sugiyono. 2013. Metode Penelitian Bisnis.

Penerbit CV. Alvabeta.

Bandung.

Tjiptono. 2005. Strategi Pemasaran.

Umar H. Riset Pemasaran dan perilaku konsumen. Jakarta: PT Gramedia Pustaka Utama. 2000. Hal: 42-9.

Wijayatiti. 2008. Strategi Meningkatkan Loyalitas Melalui Kepuasan Pelanggan. Semarang.

Zeithami, A. Valerie and M. J. Bitner. 2009. Service Marketing. New Jersey: Me Graw-Hill, inc. 